\title{
Pelatihan Jenis Dan Fungsi Lamun Di Pesisir Dalam Upaya Konservasi Lamun Di Pesisir Kecamatan Bunaken Daratan Kepada Siswa Sekolah Dasar GMIM Molas dan SD GMIM 88 Meras
}

\author{
Pience V. Maabuat ${ }^{1}$ dan Verna A. Suoth ${ }^{2}$ \\ 1)Jurusan Biologi, Fakultas Matematika Dan Ilmu Pengetahuan Alam Universitas Sam Ratulangi \\ 2) Jurusan Fisika, Fakultas Matematika dan Ilmu Pengetahuan Alam Universitas Sam Ratulangi \\ Penulis Korespondensi, Pience V Maabuat Jurusan Biologi FMIPA Universitas Sam Ratulangi Manado 95115. \\ Email: Veralyn.maabuat80@unsrat.ac.id
}

\begin{abstract}
ABSTRAK
Ekosistem lamun merupakan salah satu ekosistem penyangga yang bisa ditemukan di pesisir laut, dapat ditemui seperti padang rumput yang luas di pesisir, terdiri dari beberapa jenis ataupun tunggal yang disebut padang lamun. Keberadaannya saat ini masih memperihatinkan dengan kurangnya perhatian dalam pelestarian, dikarenakan pengetahuan akan lamun itu sendiri masih sangat minim. Hasil survey sebelumnya telah menunjukkan bahwa pengetahuan masyarakat menyangkut lamun masih kurang, baik itu anak-anak maupun sampai orang dewasa, baik itu jenis bahkan fungsi dan manfaatnya. Kegiatan pembangunan cottage, hotel bahkan aktivitas masyarakat lainnya di daerah pesisir tentu saja ikut mengambil bagian dalam mempengaruhi lingkungan pertumbuhan lamun. Untuk itu perlu adanya upaya lewat penyadaran masyarakat melalui pendidikan sejak dini pada anak sekolah dasar dalam melestararikan lamun. Mitra yang dipilih yaitu SD GMIM Molas dan SD GMIM 88 Meras di Kecamatan Bunaken Kota Manado. Sekolah merupakan sarana penting untuk meningkatkan pengetahuan tentang kehidupan yang benar dan sehat untuk menunjang kelangsungan generasi dari waktu ke waktu, seperti halnya pengetahuan akan keanekaragaman hayati laut seperti lamun. Program PKM ini bertujuan untuk 1. Meningkatkan pengetahuan guru dan siswa tentang ekosistem lamun laut (Seagrass) yang penting keberadaannya di pesisir, sebagai salah satu ekosistem penyangga yang sangat penting secara ekologis, 2. Meningkatkan kesadaran untuk melestarikan lingkungan pesisir. Metode untuk mencapai tujuan tersebut yaitu metode workshop dengan teknik ceramah/pelatihan dan pendampingan. Metode ini dilakukan secara langsung dengan tatap muka, melalui beberapa tahapan yaitu : pemberian penjelasan dengan materi ceramah dikemas secara menarik dalam bentuk power point sehingga bisa menarik perhatian peserta dan mendiskusikannya bersama dalam tanya jawab, selain itu diberikan permainan untuk melihat respon penyerapan materi kepada siswa. Guru khususnya dilatih secara bersama untuk bisa memotivasi siswa dan anggota masyarakat tentang pengetahuan yang diberikan. Hasil yang diperoleh, ada respon positif dan peningkatan pengetahuan dengan diskusi interaktif bersama siswa dan guru yang menunjukkan bahwa materi yang diberikan telah diserap dengan baik. Diharapkan kegiatan ini memberikan pengaruh yang positif sehingga kedepannya bisa lebih meningkatkan peran serta dan perhatian dalam konservasi sumberdaya pesisir laut seperti ekosistem lamun.
\end{abstract}

Kata Kunci: SD GMIM Molas, SD GMIM 88 Meras, Lamun, Bunaken, Konservasi 


\section{PENDAHULUAN}

\section{Analisis Situasi}

Lamun (seagrass) adalah satu-satunya kelompok tumbuhan berbunga yang dapat tumbuh dengan baik dalam lingkungan perairan laut dangkal (Wood et al. 1969 dalam Azkab, 1999) yang sudah sepenuhnya menyesuaikan diri untuk hidup terbenam di laut (Dahuri et al. 2004), dan seluruh proses kehidupannya berlangsung di dalam perairan laut dangkal (Susetiono, 2004). Lebih lanjut vegetasi tersebut bersama dengan komponen lainnya membentuk ekosistem lamun (seagrass ecosystem) yaitu satu sistem ekologi padang lamun yang didalamnya terjadi hubungan timbal balik antara komponen abiotik dan biotik (Azkab, 2006).

Manfaat lamun secara umum terbagi atas dua kelompok, yaitu manfaat secara ekologi dan ekonomis. Manfaat secara ekologis lebih mengarah pada fungsinya di perairan laut dangkal. Secara ekonomis dimanfaatkan oleh manusia sebagai bahan baku produk-produk tradisional seperti pupuk, cerutu, mainan anakanak, keranjang anyaman, pengisi kasur, makanan dan jaring ikan. Lamun dapat juga dimanfaatkan sebagai bahan baku produk moderen seperti penyaring limbah, stabilisator pantai, bahan baku pada pabrik kertas, dan bahan obat-obatan (Romimohtarto dan Juwana, 2001), bahan pakan ternak (Fachrul, 2007), dan Jenis $E$. acoroides dimanfaatkan oleh penduduk Kepulauan Seribu sebagai bahan makanan dari bijinya (Yudista, 2010). Manfaat lamun itu sendiri dapat dimanfaatkan sebagai sumber asam lemak (Ridlo,2004), buah lamun sebagai sumber makanan alternatif (Wakano, 2013), dan senyawa tanin sebagai antioksidan (Hagerman, 2002).

Mitra Program Kemitraan Masyarakat (PKM) yang dirangkul untuk merupakan siswa sekolah dasar Kecamatan Bunaken Daratan Kota Manado yaitu SD GMIM Syalom Molas dan SD GMIM 88 Meras. Kedua sekolah ini berada di kelurahan yang berbeda, yaitu SD GMIM Syalom berada di Kelurahan Molas. SD GMIM 88 Meras di Kelurahan Meras.

Kecamatan Bunaken Daratan masuk dalam wilayah administratif Kota Manado yang terletak paling utara. Jarak tempuh dari pusat kota Manado bisa 30 - 45 menit menggunakan kendaraan pribadi. Dahulu merupakan bagian dari Kabupaten Minahasa yang kemudian dimasukan kedalam Kota Manado berdasarkan Peraturan Pemerintah RI Nomor 22 Tahun 1988 Tentang Perubahan Batas Wilayah Kota Manado. Kecamatan Bunaken sendiri pada awalnya terdiri atas 8 Kelurahan diluar dari Kelurahan Pandu yang dulunya merupakan bagian dari Kecamatan Mapanget. Namun setelah dimekarkan, 4 Kelurahan yang berada di wilayah kepulauan telah menjadi Kecamatan Bunaken Kepulauan. Sehingga tersisa 4 Kelurahan di tambah dengan masuknya Kelurahan Pandu ke wilayah Kecamatan Bunaken. Luas Wilayah Kecamatan Bunaken adalah $=3.183,07$ ha. Batas Wilayah : Sebelah utara berbatasan dengan Kabupaten Minahasa Utara, sebelah timur berbatasan dengan Kecamatan Mapanget, sebelah selatan berbatasan dengan Kecamatan Tumintin, dan sebelah barat berbatasan dengan Kecamatan Bunaken Kepulauan dan Teluk Manado.

Hasil pengamatan di pesisir wilayah ini banyak terdapat hamparan sampah, beberapa sumber informasi menyebutkan bahwa pesisir merupakan tempat 'pembuangan akhir'. Buangan limbah rumah tangga langsung ke wilayah pesisir karena letak dapur. Hal ini tentu saja menjadi salah satu penyebab terganggunya ekosistem perairan pesisir dan bisa menyebabkan hilangnya salah satu komponen dalam rantai dan jaring makanan.

Informasi yang dikumpulkan oleh tim sebelum merencanakan program ini, yaitu kurangnya informasi menyangkut sumberdaya pesisir terutama lamun laut (Seagrass), bahkan sebagian besar hanya mengira bahwa lamun hanyalah rumput liar yang tumbuh di pesisir dengan nama lokal Galamu. Belum sepenuhnya 
paham bahwa lamun berfungsi penting di pesisir secara ekologis dan dapat dimanfaatkan sebagai bahan baku yang bernilai ekonomis.

Kurangnya pengetahuan dan pemahaman tentang lamun menyebabkan masyarakat tidak berusaha untuk menjaga kebersihan ataupun kelestariannya dengan menjaga pesisir tetap bersih dari sampah limbah rumah tangga, dan lain sebagainya. Selain itu aktivitas masyarakat yang tinggi dipesisir menjadi salah satu yang mendukung berkurangnya keberadaan lamun, selain itu lokasi pesisir yang didominasi oleh rataan terumbu karang sehingga jenis lamun tertentu tidak ditemukan tumbuh di tempat itu.

Siswa sekolah Dasar di kedua sekolah ini dipilih sebagai mitra dimaksudkan agar sejak dini ditanamkan pengetahuan tentang arti pentingnya lamun di pesisir dan bagaimana masyarakat lebih memahami arti penting suatu konservasi dimulai dari tingkat pendidikan awal yaitu sekolah dasar agar benar-benar pengetahuan yang diperoleh dapat diaplikasikan dalam kehidupan sehari-hari terlebih untuk anak cucu nantinya. Ketika pengetahuan mereka peroleh maka berbagai aktivitas yang dilakukan dapat terarah.

\section{Tujuan dan Manfaat Kegiatan}

Kegiatan ini bertujuan untuk meningkatkan pengetahuan dan kesadaran bagi guru dan siswa tentang lamun (Seagrass) yang penting keberadaannya di pesisir sebagai salah satu ekosistem penyangga yang sangat penting secara ekologis, sehingga mampu berperan aktif dalam pelestarian lingkungan pesisir.

\section{METODE PELAKSANAAN}

\section{Sasaran Kegiatan}

Sasaran kegiatan yaitu siswa sekolah dasar dan guru yang ada di Kecamatan Bunaken

\section{Lokasi Kegiatan}

SD GMIM Molas dan SD GMIM 88

Meras di kecamatan Bunaken Kota Manado

\section{Metode yang digunakan}

Kegiatan PKM ini menggunakan metode pelaksanaan seperti kegiatan sosialisasi dan pelatihan dengan tahapan sebagai berikut:

1. Kegiatan Worksop berupa penyuluhan dan pelatihan motivator; memberikan penyuluhan berupa bagaimana mengenal lamun di perairan, arti pentinya lamun, dan pengaruh aktivitas manusia bagi keberadaan lamun, serta arti pentingnya konservasi.

2. Diskusi interaktif dengan peserta

3. Visualisasi tentang lingkungan pesisir dan biota dengan permainan gambar

4. Pemberian reward/hadiah bagi peserta yang aktif menjawab dengan benar

5. Pemberian reward berupa sertifikat untuk peserta guru.

\section{HASIL DAN PEMBAHASAN}

Kegiatan yang dilaksanak di SD GMIM Molas dan SD GMIM 88 Meras berlangsung dengan baik, dilihat dari ketertarikan dan antusiasnya peserta mulai saat pemberian materi sampai permainan dan penutupan kegiatan.

\section{Pemberian Penjelasan}

Pemberian materi diberikan secara tatap muka dengan metode ceramah, dibatasi pada jenis dan fungsi lamun saja, akan tetapi dikaitkan interaksi dengan lingkungan, baik itu kegiatan masyarakat di pesisir dan lainnya yang memiliki pengaruh terhadap kehidupan lamun. Dijelaskan tentang jenis-jenis lamun yang ada di pesisir khususnya kecamatan Bunaken, diantaranya yaitu ada Enhalus acoroides, Thalassia hemprichii, Cymodocea sp, halodule sp, Halophila ovalis. Disebutkan pula bahwa saat ini keberadaan ekosistem padang lamun perlu mendapat perhatian, selain ekosistem lainnya seperti terumbu karang dan mangrove. Fungsi lamun itu sendiri sangat penting, yaitu menjadi tempat asuhan bagi biota laut, tempat mencari makan, berfungsi menstabilkan perairan dari ombak, dan lainnya. Selain itu memiliki manfaat secara 
Jurnal Pengabdian Multidisiplin

ekonomis, sebagai bahan dasar obat-obatan bahkan sebagai karya tangan yang memiliki nilai jual, Selain itu materi juga dikaitkan dengan biota yang ada di laut yang memanfaatkan lamun, baik itu yang langka ataupun tidak.

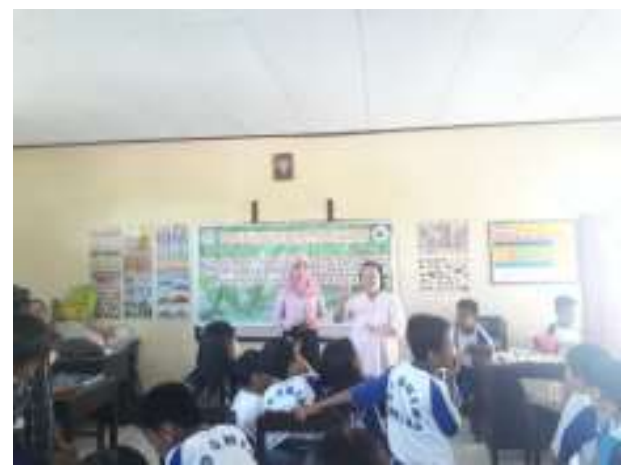

Gambar 1. Pemberian Pendidikan dalam Bentuk Ceramah

\section{Diskusi Interaktif dengan Siswa}

Diskusi ini dimaksudkan untuk mengukur tingkat serapan materi yang telah diberikan, ternyata hasil yang diperoleh adalah respon siswa yang begitu antusia menjawab dan memberikan alasannya. Saat diberikan pertanyaan tentang jenis lamun, mereka sudah bisa menjawabnya sesuai dengan yang dijelaskan dan gambar yang ditampilkan.

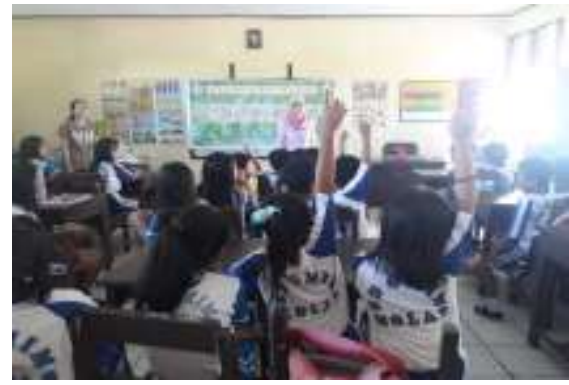

Gambar 2. Diskusi Interaktif

\section{Visualisasi tentang Lingkungan}

Kegiatan ini dikemas dalam bentuk permainan yang mencari jawaban dari pertanyaan seoutar lingkungan perairan, juga ditambah dengan biota yang langka dan tidak, dipilih lima orang siswa untuk terlibat dalam permainan ini. Dari lima siswa empat menjawab dengan benar semua pertanyaan, dan satu siswa hanya menyelesaikan beberapa gambar saja, ada satu yang salah.

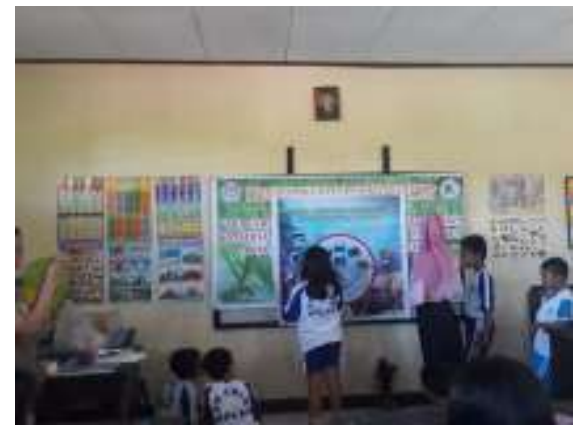

Gambar 3. Visualisasi Lewat Gambar dan Permainan

\section{Pemberian Reward}

Siswa yang mampu menjawab pertanyaan dari tim pelaksana diberikan

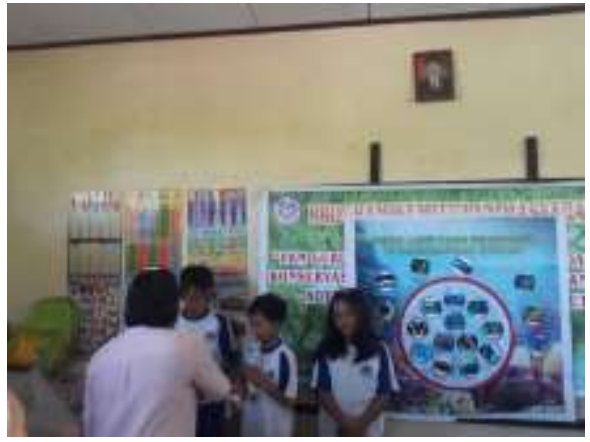

Gambar 4. Pemberian Hadiah

Kegiatan penyuluhan tentang sumberdaya alam yang terkait erat dengan pelestarian lingkungan, tentunya menjadi daya Tarik tersendiri bagi siswa sekolah dasar yang masih belajar tentang lingkungan sekitarnya. Sangat baik kegiatan seperti ini dilaksanakan melihat respon yang diterima dan nantinya dapat menjadi bekal bagi para siswa ketika akan terjun ke lapangan atau saat akan berinteraksi dengan lingkungan sekitarnya, terutama di pesisir.

\section{KESIMPULAN DAN SARAN}

\section{Kesimpulan}


1. Siswa yang ada di SD GMIM 88 Meras dan SD GMIM Molas Kecamatan Bunaken Manado dapat menyerap materi tentang jenis dan fungsi lamun dengan baik baik secara lisan maupun tulisan dengan menggunakan alat bantu berupa power point dan alat peraga berupa kerton bergambar untuk menebak.

2. Hampir seluruh siswa dapat bertukar pikiran, pandangan dan pengetahuannya, serta mampu bekerjasama dalam menyelesaikan setiap pertanyaan dan mampu menjelaskannya lewat visual.

3. Para siswa dan guru lebih aktif dan termotivasi dalam mengikuti kegiatan penyuluhan ini.

\section{Saran}

Kegiatan ini penting dilaksanakan di lokasi lainnya, agar masyarakat sejak dini mengetahui tentang arti pentingnya keberadaan lamun di lingkungan pesisir, sehingga lingkungan pesisir tidak lagi dijadikan sebagai tempat pembuangan akhir, kedepannya juga diperlukan alat peraga untuk budidaya lamun.

\section{UCAPAN TERIMA KASIH}

Kegiatan ini terlaksana berkat bantuan banyak orang, mulai dari persiapan sampai terlaksananya program kemitraan masyarakat ini. Secara khusus tim menyampaikan terima kasih kepada ibu Sukmayanti, S.Hut dari Balai Taman Nasional Bunaken yang telah menjadi salah satu pemateri, mahasiswa yang ikut ambil bagiandalam pekerjaan di lapangan, Natalia, Melisa dan silsia. Diucapkan terima kasih juga kepada Pimpinan LPPM Unsrat Manado, yang telah mendanai pendidikan dan penyuluhan ini melalui Program KemitraanvMasyarakat (PKM) dan Pimpinan Universitas Sam Ratulangi Manado
Azkab,H. 1999. Petunjuk Penamaan Lamun.

$\begin{array}{lll}\text { Oseana } & \text { Vol XIII (1); } & \text { 10-21. } \\ \mathrm{P}_{3} \mathrm{O} & \text { LIPI, Jakarta }\end{array}$

Azkab, M.H. 2006. Ada Apa dengan Lamun. Oseana Vol XXXI (3); 4555. $\quad \mathrm{P}_{3} \mathrm{O}$ LIPI, Jakarta

Dahuri, R., J. Rais, S. P. Ginting., M.J. Sitepu. 2004. Pengelolaan Sumber daya wilayah pesisir dan lautan secara terpadu. Pradya Paramita, Jakarta.

Fachrul, M.F. 2007. Metode Sampling Bioekologi. Bumi Aksara, Jakarta.

Hagerman, A.E. 2002. Tannin Handbook. Departement of Chemistry and Biochemistry, Miami University.

Susetiono. 2004. Fauna Padang Lamun Tanjung Merah Selat Lembeh. Buku, 106 hal. Pusat Penelitian Oseanografi-LIPI, Jakarta.

Wakano, D. 2013. Seagrass enhalus acoroides fruit utilization as alternative Food Sources Lomin village community east of seram. Pemanfaatan buah lamun Enhalus acoroides sebagai sumber makanan alternatif Masyarakat desa Lomin seram bagian timur. Fmipa Universitas Pattimura (Prosiding).

Yudista, A. 2010. Lamun.

Http://www. Tnl. Kepulauan Seribu.net/indeks.php?which=11 [2 Juni 2011]

\section{DAFTAR PUSTAKA}

